FACTA UNIVERSITATIS

Series: Mechanical Engineering Vol. 15, N 1, 2017, pp. 107 - 117

DOI: 10.22190/FUME160831005R

Original scientific paper

\title{
DEEP DRAWING TECHNOLOGY WITH WALL IRONING IN MASS PACKAGING INDUSTRY
}

UDC 621.7:005.4

\author{
Saša Ranđelović ${ }^{1}$, Mladomir Milutinović ${ }^{2}$, Vladislav Blagojević ${ }^{1}$ \\ ${ }^{1}$ University of Niš, Faculty of Mechanical Engineering, Serbia \\ ${ }^{2}$ University of Novi Sad, Faculty of Technical Sciences, Serbia
}

\begin{abstract}
Aluminum is a metal that is being increasingly used in the packaging industry in the modern metal forming technology, but it also provides a good opportunity for effective advertising and product promotion. Processing technologies for aluminum plastic deformation ensure superior packaging that meets the most rigorous demands in the food, pharmaceutical, chemical, and other industries. It is the case of mass production with very little material loss that offers the possibility of multiple recycling. On the other hand, today's products for general purpose consumers cannot be imagined without aggressive advertising that has a major impact on customers. Modern graphics techniques for printing images and different basic surfaces offer great opportunities that manufacturers use widely in the promotion and sale of their products.
\end{abstract}

Key Words: Can, Deep Drawing, Packaging, Product Management, Graphic Design

\section{INTRODUCTION}

Large investments in research and primary aluminum processing, especially in the production of finished aluminum products, have led to the aluminum industry being the indicator of the most powerful world economies today. One can increasingly hear the information regarding aluminum consumption per capita, the share of aluminum per automobile, the amount of aluminum in the construction industry, or in everyday use, etc. Naturally, all of this is further encouraged by the fact that aluminum is very convenient for getting the finest products which now meet the most rigorous demands of the market, i.e. the customer [1].

Received August 31, 2016 / Accepted December 20, 2016

Corresponding author: Saša S. Ranđelović

Faculty of Mechanical Engineering, Department of Production Engineering, A. Medvedeva 14, 18000 Niš

E-mail: sassa@masfak.ni.ac.rs 
Industrial packaging of food products and fast food delivery to the customer with unchanged characteristics is impossible today without the use of various types of foil, cans, wrappers, and curlers, which are all based on aluminum sheet and its finished products. Today, most current industry packaging based on aluminum saves energy in the production and transportation of products [2]. The weight of the beverage packaging in cans, for example 0.331 , is only $5 \%$ of the weight of the beverage, while in the case of glass packaging the weight is almost identical. Cans are promoted as packing material impervious to light, the fastest to cool, simple to open, while keeping the flavor of drinks well, but also as the only packaging based on metal that is $100 \%$ recyclable, which significantly contributes to the preservation of the environment.

Sheet metal forming is one of the most important manufacturing processes for mass production, especially in the automotive and aerospace industries, yet with application in many other production processes as well. Deep drawing and ironing are the most frequently used manufacturing processes to produce thin-walled cans. Those who are interested in learning more about metal forming mechanics can refer to certain excellent books [3-5].

Many investigations show that there is a thickness reduction rate in which the ironing process becomes unstable $[6,7]$. This leads to a variation of thickness along the can in the circumferential direction. These problems are generally solved in the industry by trial and error, with changes in the material geometry [8].

$\mathrm{Gu}$ et al. [9] presented an optimization method for mass customization products which seeks to maximize the manufacturing efficiency. This model suggests increasing the commonality on different bill of materials levels and thereby maximizing the number of "mass production steps" and minimizing the customization steps during the manufacturing process. While this model would help in improving manufacturing efficiency given a certain set of functional requirements, it does not address balancing the customer demand for customization with the manufacturing efficiency.

Kumar [10] formulated a number of metrics for customization, mass production and modularity, thereby measuring the number of modules, combinations and theoretical production volume per module. The main metrics are: average number of options per feature, maximum number of configurations, average number of configurations per customer, degree of customization and average demand per option per period. These metrics are useful in relation to describing the variety of a product family and yet they are less useful in relation to assessing whether some options are configured less frequently than others potentially rendering them less profitable. Furthermore, these methods do not enable assessment of whether the variety offered is actually the variety demanded by customers.

\section{TeChNOLOGY OF MASS PROduction OF CANS}

An infinite continuously-rolled strip of aluminum sheet is introduced in a combined tool for blanking a workpiece that is immediately subjected to deep drawing. This process of refining metal requires very tight tolerances of material thickness with a special coating layer so as to minimize the coefficient of friction to $\mu=0.08$.

The tin plate strip is unwound, its surface coated with a thin film of lubricant and the strip continuously conveyed to the deep-drawing press. The full technological capacity yields an almost unbelievable productivity of 1700 pieces per minute, or 650 million per 
year. At first a blank is cut out $(D=164 \mathrm{~mm}, s=0.25 \mathrm{~mm})$ at each individual tool of the press; the drawing ram then presses this blank through the draw ring to form a cup with the diameter of $100 \mathrm{~mm}$ and height of $41 \mathrm{~mm}$ (Fig. 1). Deep drawing is a metal forming process targeted for the production of thin walled cup/can shape objects through a combined compression-tension operation [11-13]. As shown in Fig. 1, a blank is forced into a die cavity by a punch and it assumes the shape of the punch while being held by the blank holder. The process normally maintains the thickness of the sheet metal and can be used for shallow or deep parts. The tool is made up of 9 to 10 individual tools (for stamping, deep drawing and ironing) which are arranged next to each other.

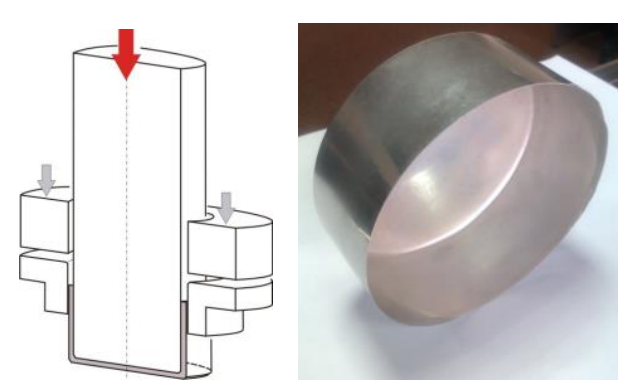

Fig. 1 Finished part after deep drawing process

Critical stress $R_{\rho_{\text {Imax }}}$ is normal stress which occurs in the radial direction, where the workpiece material suffers an elongation [3, 4]. The maximum stress in the first operation of drawing occurs at the moment of full coverage of the rounded edges of tools upon which plastic deformation takes place only through the radius of the matrix [12]:

$$
R_{\rho_{i \max }}=\left(1,1 K_{s r} \ln \frac{R_{s}}{R}+\frac{\mu F_{d}}{\pi R_{s} s}+K_{s r} \frac{s}{2 r_{M}+s}\right)(1+1,6 \mu),
$$

where $K_{s r}$ is the mean true von Mises stress of the material workpiece, $R_{s}$ is the radius of the workpiece at the moment when the maximal force is identified, $R$ and $d_{i}$ represent the radius and the diameter of the deep drawing element at the first and $i^{\text {th }}$ operation, respectively, $\mu$ is the coefficient of friction, $F_{d}$ is the force at the blank holder, $r_{M}$ the radius on the die matrix and $R_{m}$ is the maximal stress extension of the material workpiece.

The cup is held by the variable pressure of the blank holder, during deep drawing process, to prevent wrinkles with which the flow of the manufacturing process is not possible [12]. Wrinkles are caused by excessive clearance between the punch and the die and also due to an improper value of pressure of the blank holder during deep drawing process and an incorrect value of the punch radius. The proper pressure value is determined based on the following equation:

$$
p_{d}=0,25\left[\left(\frac{D_{0}}{d_{i}}-1\right)^{2}+\frac{d_{i}}{200 s}\right] R_{m},
$$

where $D_{0}$ is the diameter of workpiece and $d_{i}$ the diameter of deep drawing. 
In certain applications, parts can be deep-drawn in several steps by redrawing. At each step, the cup becomes longer (deeper) and its diameter is reduced. However, if the wall thickness needs to be reduced as well, an ironing operation is implemented. In this process, as the part is redrawn, it is forced through an ironing ring (like an extra die) placed inside the cavity (Fig. 2).

Ironing is the preferred operation for the fabrication of beverage cans $[5,6]$. The cup is conveyed to the wall-ironing tool from the top. The ram first pushes it through the redraw ring to reduce its diameter of $65 \mathrm{~mm}$ to the punch diameter whilst retaining the sheet thickness constant at $0.25 \mathrm{~mm}$.

There is a gap between the punch and the wall-ironing rings 1 to 4 immediately after the redraw ring where the wall thickness of the can is reduced by "ironing" the thin wall (s $=0.15 \mathrm{~mm}$ ) and consequently lengthening the can to $170 \mathrm{~mm}$.
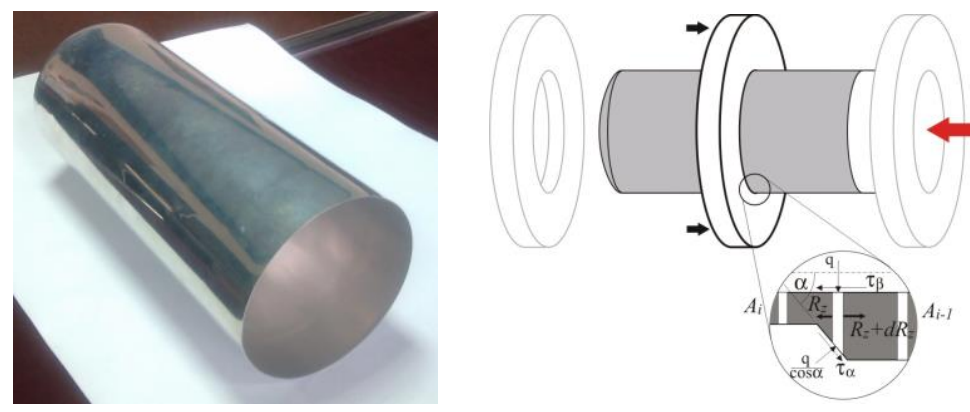

Fig. 2 Ironing the can wall

For typical ironing stress the stress balance is set in the axial direction [5, 12]. Especially considered is the conical part of the tool where there is a change in the thickness of the cylindrical wall and the output section with reduced can wall thickness:

$$
\begin{aligned}
& \left(R_{z}+d R_{z}\right)\left((x+d x)^{2}-r_{2}^{2}\right) \pi-R_{z}\left(x^{2}-r_{2}^{2}\right) \pi-2 \pi r_{2} \tau_{\beta} \frac{d x}{\operatorname{tg} \alpha}+ \\
& \tau_{\alpha} \cdot \cos \alpha \frac{d x}{\sin \alpha} 2 \pi x+\mu_{1} \frac{q}{\cos \alpha} \cdot \sin \alpha \cdot \frac{d x}{\sin \alpha} \cdot 2 \pi x=0
\end{aligned}
$$

where $\alpha$ is the die angle, $R_{z}$ is the axial stress inside the ironing wall, $r_{2}=0.5\left(r_{a}+r_{b}\right)$ is the mean value of the inner radius of the workpiece, $x$ is variable diameter, $\tau_{\alpha}$ is the tangential contact stresses on the die, while $\tau_{\beta}$ the tangential contact stresses on the punch and, finally, $q$ is the normal stress as a consequence of continuous load.

From the above equation of the balance of forces, it can be seen that the frictional force on the contact surface between the punch and materials process helps deep drawing. The explanation lies in the fact that the focus of deformation of the material is flowing along the punch, in the opposite direction to the movement, but with the direction of the force of friction the same as the direction of the force on the punch. For these reasons, the surface should be punched with greater roughness, if permitted by the required quality of the inner surface of the can, in order to maximize the positive impact of friction on that part of the focus of deformation. Substituting tangential contact stresses, $\tau_{\alpha}$ and $\tau_{\beta}$, which are proportional to the normal stress $q$ : 


$$
\tau_{\alpha}=\mu_{1} \frac{q}{\cos \alpha} \text { and } \tau_{\beta}=\mu_{2} \cdot q
$$

where $\mu_{1}$ is the friction coefficient at plastic deformation and $\mu_{2}$ is the friction coefficient at sliding, the normal stress with the plasticity conditions for the plane strain state reads:

$$
q=\frac{K_{r}-R_{z}}{1-\mu_{1} \cdot \operatorname{tg} \alpha}
$$

where $K_{r}$ is the true von-Mises stress for plane deformation state.

The separated element of volume in the focus of deformation from the previous balance equation (Fig. 2) takes the form:

$$
2 R_{z} \cdot x d x+\left(x^{2}-r_{2}^{2}\right) d R_{z}+2 \cdot b \cdot x_{z}\left(K_{r}-R_{z}\right) d x=0
$$

and at the entrance of the conical part of the focus of deformation the normal tensile stress $R_{z}$ has a value of 0 to make its exit receive maximum value $R_{p}$ :

$$
R_{p}=1.155 K_{s r} \frac{b}{b-1}\left[1-\left(\frac{A_{i}}{A_{i-1}}\right)^{b-1}\right]
$$

where $b=1 / \cos \alpha+\mu / \sin \alpha-\mu / n \cdot \operatorname{tg} \alpha$ is the coefficient which depends on the matrix angle and the clearance between the punch and the ironing die, and $\mu$ is the friction coefficient $[8,9,12] . A_{i-1}$ and $A_{i}$ are the ring areas of cross section at the wall of the can before and after the reduction in thickness, respectively.

On entering the first ironing die, the material thickness has not yet been reduced, and therefore does not show any strain. As the material passes through the ironing die, there is a rise in the ironing force up to the value indicated in Fig. 3, where force is plotted in relation to the reduction in thickness. In subsequent ironings, this force continues to increase up to the value of the maximum thickness reduction. Fig. 3 shows the influence of the ironing die angle on the ironing force compared to the deformation of thickness or deformation degree. A small variation in force can be seen for a considerable increase in the ironing die angle, where this variation reaches almost zero at the finished ironing $[12,13]$.

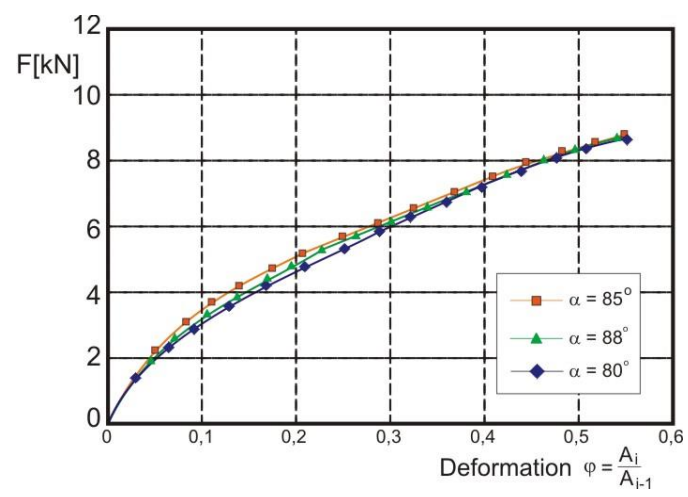

Fig. 3 Comparison of drawing forces for different values of the ironing die angle 
As can be seen in Fig. 4a, the friction coefficient between the material and the ironing die significantly influences the ironing force, and at every stage of ironing this difference increases further. This shows that the greater force applied to the material, the greater the influence of friction on the process. In Fig. $4 \mathrm{~b}$, it is shown that for a greater clearance there is a reduction in the ironing deep drawing force and for a smaller clearance there is an increased force, where the greatest influence of the clearance is in the finished ironing. This shows that if there is a misalignment between the punch and the ironing die, there will be a significant imbalance in force and consequent excessive wear of the punch and the ironing die [14].

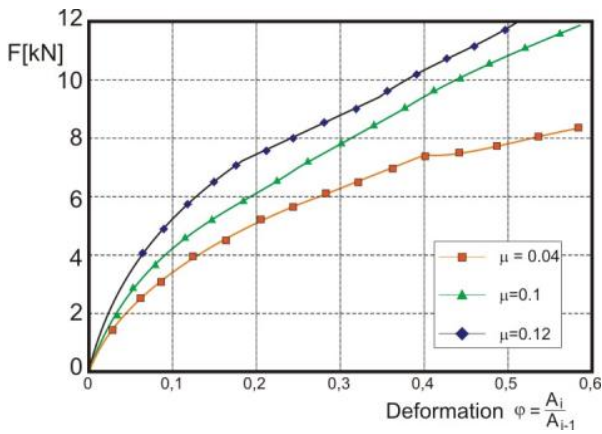

a)

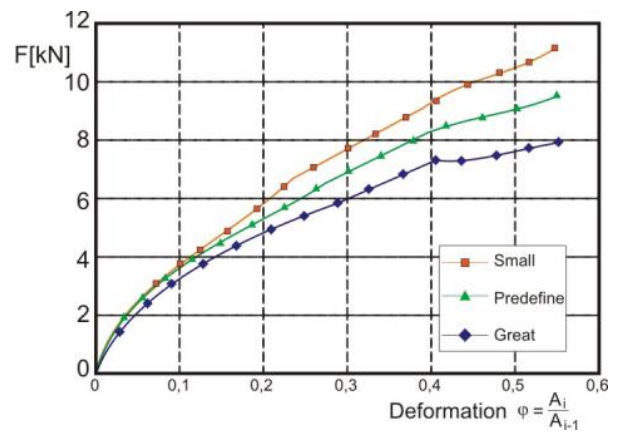

b)

Fig. 4 Drawing force comparison for different values of:

a) friction coefficient and b) clearance

In order for the can to have the necessary strength during transport, process filling and sealing, it is necessary that the bottom of the can gets a much higher stiffness of the wall. This is achieved by forming the bottom with a characteristic profile (Fig. 5) by deep drawing technology in future operations.

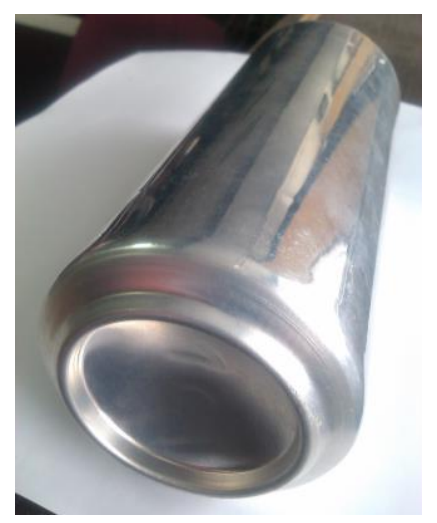

Fig. 5 Increased stiffness on the bottom of the can 
At the end of this stroke, the punch with the can comes into contact with the base paneling tool and the can base is formed. When the ram is withdrawn, the can is removed from the punch by a stripper and conveyed out of the machine via an unloader belt. All lubricants from a metal surface in previous forming process must be removed by the process of washing. The wallironing lubricant used in the can forming process is removed prior to coating the can internally and externally. The cans are transported to the washer on a wide belt and conveyed through several washing chambers upside down.

In this way the outside of the can is rinsed with tap water supplied through the jets located at the top and the inside of the can by the jets located at the bottom. Immediately downstream of the washing unit, the can is dried with dry air at a temperature of approximately $200{ }^{\circ} \mathrm{C}$ in the drying oven.

\section{GRAPHIC DESIGN AND PRINTING THE OUTSIDE OF THE CAN}

From the above, it is not easy to get a superior aluminum product such as a can, because this is a high quality, high productivity, very cheap and reliable product. Metal forming technology meets the basic requirements of customers which have been considered conventional and common for many years now. What remains is the most sensitive part, how to reach the customer as soon as possible and earn his trust in the future on the global market. Surely the main role is played by the contents of the can, its quality and price [15]. But one element, which has become increasingly crucial, is the visual effect (Fig. 6). Market conditions, strong competition, the modern way of life are all elements that affect the finished product. The cans are coated on the outside as protection against atmospheric influence and in order to apply a decorative design [16]. White, gold or transparent coating as well as aluminum-colored coating can be used according to customer specifications gained by various research and analyses of the market. Nowadays, the coatings are water-based which is in accordance with modern requirements of environmental protection.
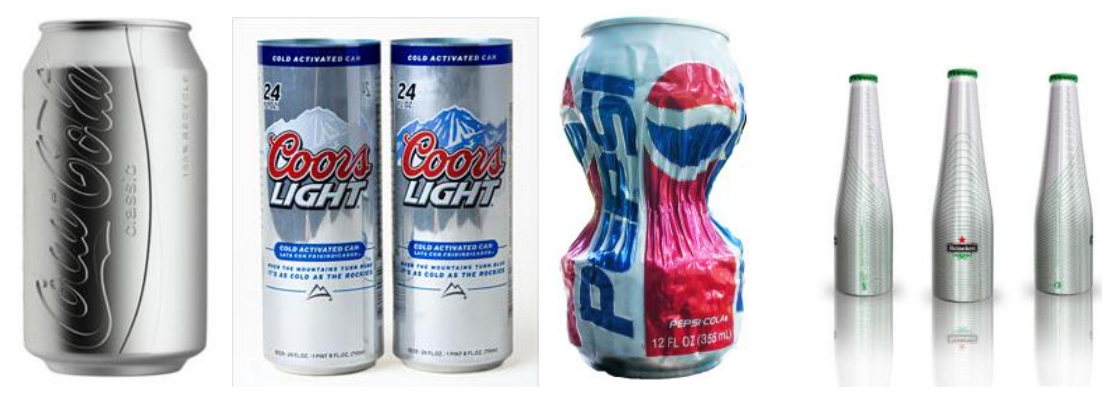

Fig. 6 Sample of modern thermo graphic design and free shape (courtesy: Chromatic Technologies inc.)

Cans are spaced by an intake wheel and drawn on to the coating mandrel of the mandrel wheel by means of vacuum. They are then set in rotation around their own axis by the rotation belt. The coating film on the coater cylinder is then transferred to the cans positioned on the rotating coating mandrels (Fig. 7). The coating is pumped from a 
coating container to the engraved cylinder which transfers the appropriate quantity to the rubber-coated coating cylinder where it is transferred to the cans. The coated cans are then blown off the coating mandrels and transported to the drying oven on a magnetic conveyor belt.
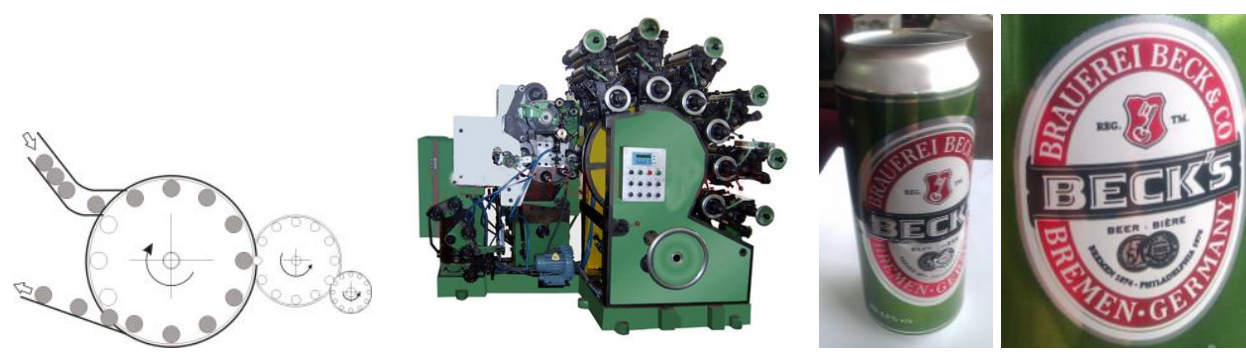

Fig. 7 General principle of painting cans and technical solution of best printing

While the market recognizes standard cans found in shops and shopping malls, which are produced in large series, today one can very often find cans that are made in far smaller quantities. These are specially designed and shaped packages, with regard to their volume, shape and color, or to the occasion of a social event, festivals and gatherings, and are prepared in relatively small series with the current messages. Complex and distributed innovation processes with a multitude actors call for modern information and communication technologies as supporting factors for virtualization and collaborative innovation management [15]. Large manufacturers are now facing major business challenges. They have the opportunity to demonstrate their superiority in the market conditions with harsh global competition, and demonstrate their readiness to respond to the project team and complex requirements (Fig. 6).

They must offer effective design solutions, which need to be very fast in these conditions and found quickly on the product line, while offering innovative solutions with superior quality at the same time. Products are customized both in appearance and excellent print quality, but now this goes a step further, where an effective form or effect (thermo cans which can change color) achieve an even stronger impact on the potential buyer. This is a challenge that requires special technological solutions, but also the superior quality that will leave potential customers breathless at a given moment. Multidisciplinarity, flexibility, and the real emergency of practice, primarily business results, are very important here. These requirements are today often met by specialized design teams and agencies that take over the whole business of design and development of such products, in all their aspects, for the global market.

\section{Production Process Management for Mass Customization}

The described technology with the process parameters aims to illustrate the capabilities of a modern and complex technology that is now widely applied. Almost unbelievable data only indicate the kind of level to which this process has been brought without any opportunity for error. Design and development are entrusted to the main team with extensive experience, which distributes its proven results and achievements to the lowest level of implementation [17, 18]. The technical support, in cooperation with various external partners, has developed new 
measuring systems to enhance process quality: sensor systems to carry out machine diagnosis in wall-ironing presses, sensor systems to monitor axial force and compressed air support in the die-necker, etc. [19]. New product and process instrumentation and control equipment are developed at the center laboratory and then installed as standard quality assurance equipment at production plants.

Various sources of ideas are systematically evaluated. These also include the modified requirements of our customers [20]. The development center team collaborates closely with its customers in order to gain precise knowledge of and understand their needs and requirements (QFD methods). In addition, they want not only to implement innovative solutions but also to keep them exclusively for their customers (Fig. 6).

A very small number of employees and teamwork come to the fore in modern automated systems. Process measuring equipment comprises measuring systems to measure and monitor the individual parameters of the production process and monitor compliance with process tolerances in real time. These include, for example, drawing force, deep drawing acceleration, length of cans, position tool, air pressure, temperature, etc. (Fig. 8).

In the implementation phase of production, only the given parameters are monitored via statistical process control charts where one can see their current trend and deviation, which indicate timely intervention, correction or the possible replacement of the critical elements.
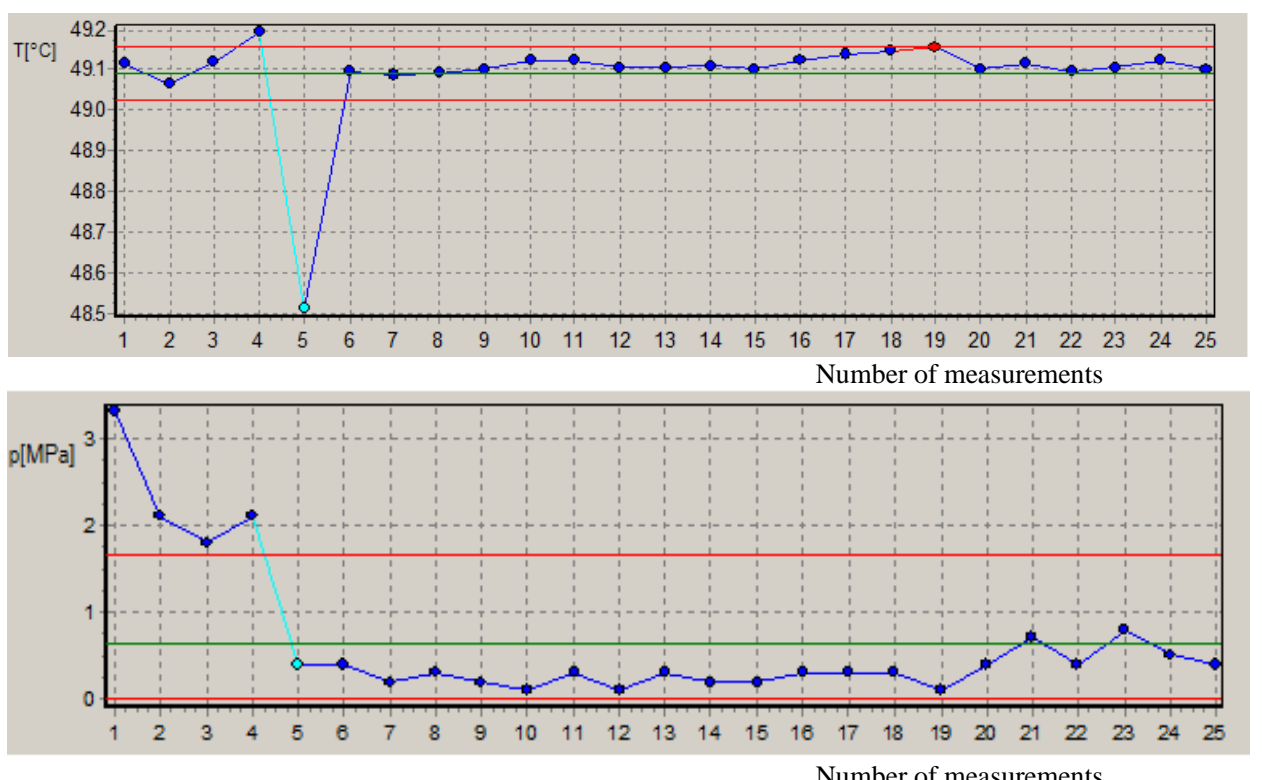

Fig. 8 SPC control chart for production parameters, washing temperature with target value of $49.1^{\circ} \mathrm{C}$ and pressure with target value of $0.7 \mathrm{MPa}$

The generated problems, daily reports and data production are carefully analyzed in order to keep the system in the specified control limits. It goes as far as having corrections, replacement of necessary tools and interventions on individual elements all performed at a 
central workplace, so as to correct, return and assemble the tools in one place, with the aim of reducing losses and empty work strokes.

Construction, design, and testing of machines, devices, tools and equipment are centralized and they are granted to highly skilled teams of professionals. Their results and solutions are closely and strictly connected with the industrial exploitation, and are implemented only after market conditions and competition moves have been assessed.

\section{CONCLUSION}

A production system designed in this way shows great robustness and resilience to disturbances that are always present. Its flexibility, on the one hand, and the speed of response to disturbance, on the other, is designed exclusively for mass production.

The production process for aluminum cans is already technologically very advanced, and therefore it is useful to have the most information possible on material and tooling in order to optimize it.

The tooling force calculations, measurements and analysis show that the material is not being exploited to the highest requirements, and therefore a diagram is constructed (Fig. 3, 4a, 4b) which shows that if the production wants to reduce the final can thickness, there is a possibility to explore more of the material without causing defects.

It was shown, as expected, that the friction coefficient and the clearance between the punch and the ironing die have great influence on the deep drawing force. The ironing die angle, however, did not prove to be essential to the process, and did not influence the deep drawing force very much.

Each business team only knows its job, which is a very narrow scope of knowledge and skills that are acquired and grown in a very long time. The fact that in Europe tool repair and correction are performed in a single place, or that there are teams which specialize only in quick tool change and assembly speaks volumes. For example, design and development are centralized and located in the United States and Germany (Bonn) for all production capacity. With the above-mentioned productivity losses, the delay in time must be minimal. Orientation towards the market is reflected in following the latest trends and design effects that can be detected on the can. Customers appropriate such products and treat them as an integral part of their daily consumer basket. Viewed from the perspective of business success, this has been the goal all along - to create a product that will generate large profits in the global market in the long run.

Acknowledgements: This paper is part of the research funded by Ball Packaging Europe Belgrade, Republic of Serbia. 


\section{REFERENCES}

1. Majstorović, V., 2001, Quality Management (in Serbian), Mechanical Engineering Faculty, Beograd, 390 p.

2. Eikelenberg, N., Kok, I., 2003, Tempelman, E., The role of product design in closing material loops, Proc. of the 3th international Symposium on Environmentally Conscious Design and Inverse Manufacturing, Tokyo, Japan, December 8-11, pp. 605-610.

3. Altan, T., Tekkaya, A.E., 2012, Sheet Metal Forming Fundamentals, ASM International, 296 p.

4. Banabic, D., 2010, Sheet Metal Forming Processes, Springer, 318 p.

5. Marciniak, Z., Duncan, J. L., Hu, S. J., 2002, Mechanics of Sheet Metal Forming, second ed. Butterworth-Heinemann, $228 \mathrm{p}$.

6. Courbon, J., 2003, Damage evolution in a compressive forming process: ironing of beverage cans, Scr. Mater., 48, pp. 1519-1524.

7. Kampus, Z., Kuzman, K., 1995, Analysis of the factors influencing the geometrical shape of workpieces produced by ironing, J. Mater. Process. Technol., 49, pp. 313-332.

8. Hackworth, M. R., Henshaw, J. M., 2000, A pressure vessel fracture mechanics study of the aluminum beverage can, Eng. Frac. Mech., 65, pp. 525-539.

9. Gu, X. J., Qi, G. N., Yang, Z. X., Zheng G. J, 2002, Research of the Optimization Methods for Mass Customization, J. Mater. Process. Technol., 129(1-3), pp. 507-512.

10. Kumar, A., 2004, Mass Customization: Metrics and Modularity, International journal of flexible manufacturing systems, 16, pp. 287-311.

11. Lee M.S., Kim S.J., Lim O.D., Kang C.G., 2016, The effect process parameters on epoxy flow behavior and formability with CR340/CFRP composites by different laminating in deep drawing process, J. Mater. Process.Technol., 229, pp. 275-285.

12. Lange, K., 1985, Handbook of metal forming, SME, McGraw-Hill, $1210 \mathrm{p}$.

13. Gotoh, M., Kim, Y.S., Yamashita, M., 2003, A fundamental study of can forming by the stretch-drawing process, J. Mater. Process.Technol., 138, pp. 545-550.

14. Ragab, M.S., Orban, H.Z., 2000, Effect of ironing on the residual stresses in deep drawn cups, J. Mater. Process. Technol., 99, pp. 54-61.

15. Franke N., Piller F., 2004, Toolkits for user innovation and design: an exploration of user interaction and value creation, J. of Prod. Innov. Manag., 21(6), pp. 401-415.

16. Laing, S., Masoodian, M., 2016, A study of the influence of visual imagery on graphic design ideation, Design Studies, 45, pp.187-209.

17. Ranđelović, S., 2008, The new product development for mass customization on the base integrated process model, Proc. $3^{\text {rd }}$ International Conference on MCP - CE, Palic - Novi Sad, Serbia, pp. 149-153.

18. Ranđelović, S, Denić, B, Mladenović, S, Đorđević, G, 2010, Aluminium industry, chance for mass customization and advancement of small enterprises, Proc. $4^{\text {th }}$ International Conference MCP - CE, Novi Sad, Serbia, pp. 130-134.

19. Antonio, K., Lau W., 2011, Critical success factors in managing modular production design: Six company case studies in Hong Kong, China, and Singapore, J. of Eng. and Technol. Manag., 28, pp. 168-183.

20. Ross, Ph J., 1996, Taguchi Techniques for Quality Engineering, McGraw-Hill, 455 p. 